\title{
As Políticas de Turismo no Brasil nos Anos Noventa
}

\section{The Tourism Policy in Brazil in the Nineties}

Fernando Meloni de Oliveira ${ }^{1}$

\section{Resumo}

O artigo traça um panorama e apresenta uma reflexão sobre as políticas públicas de turismo no Brasil, ao longo da década de 1990. O primeiro aspecto enfocado é a gênese destas políticas. São abordados, na seqüência, os principais planos e intervenções publicas, nos âmbitos federal e regional, e as formas de financiamento público surgidas para este segmento. Após o exame crítico de alguns indicadores e dos principais impactos das políticas, conclui-se que a desregulamentação econômica e o direcionamento da política de turismo para o aumento da captação dos fluxos turísticos externos foram, em diversos aspectos, mal estruturados e equivocados.

Palavras-chave: turismo; políticas públicas; desenvolvimento social e econômico.

\begin{abstract}
The article traces a panorama and presents a reflection on the public politics of tourism in Brazil, to the long one of the decade of 1990. The first focused aspect is the genesis of these politics. They are boarded, in the sequence, the main plans and public interventions, in the scopes federal and regional, and the appeared forms of public financing for this segment. After the critical examination of some pointers and the main impacts of the politics, is concluded that the economic deregulation and the aiming of the politics of tourism for the increase of the captation of the external tourist flows had been, in diverse aspects, badly structuralized and mistaken.
\end{abstract}

Keywords: tourism; public policy; social and economic development.

\section{Introdução}

Ao longo dos últimos anos, por razões variadas, as atividades de turismo apresentaram um grande desenvolvimento em todo mundo, a despeito das crises socioeconômicas e da crescente instabilidade política trazida pelos recorrentes conflitos internacionais. No Brasil, esta tendência não se mostrou diferente e os impactos do crescimento do turismo foram sentidos, em especial, em diversas capitais do país, vislumbrando-se apoios e investimentos, tanto do setor público quanto do setor privado.

\footnotetext{
${ }^{1}$ Bacharelado em Ciências Sociais - Política - pelo Instituto de Filosofia e Ciências Humanas da Universidade Estadual de Campinas - UNICAMP. Mestrando em Desenvolvimento Econômico - Economia Social e do Trabalho - no Instituto de Economia da UNICAMP. E-mail: fernandomeloni@uol.com.br
} 
Seja pelas oportunidades de crescimento econômico e de desenvolvimento sociocultural, seja pelas conseqüências negativas que é capaz de produzir, o turismo tem com isso ganhado (e merece) cada vez mais espaço entre as preocupações dos atores governamentais. Assim, além de todo o debate hoje encontrado a respeito do desenvolvimento do turismo no país, é preciso aumentar os esforços para avaliar e refletir sobre o papel do Estado brasileiro neste processo.

A principal tentativa do presente trabalho é articular diferentes dados e interpretações sobre vários dos aspectos que englobam as atividades de turismo no país, na década de 1990, e compor uma narrativa analítica do desempenho do que podemos chamar de Políticas Públicas de Turismo. De início, pretende-se desviar a atenção do leitor para dois pontos importantes: o primeiro, a respeito do objeto em questão e o segundo, sobre a estrutura da análise desenvolvida e suas limitações.

Uma das primeiras dificuldades inerentes ao estudo do turismo é a delimitação do que consiste esta atividade e a forma como ela pode ser mensurada ${ }^{2}$. Enquanto um processo social dinâmico, a avaliação de seus efeitos é complexa e restrita. Mesmo do ponto de vista de uma análise estritamente econômica, as atividades de turismo compõem-se ou integram-se com outros subsetores do terciário (transporte, hospedagem, alimentação e entretenimento) o que, de fato, torna a sua aferição um tanto quanto inexata. Talvez por esses motivos, o número de estudos e estatísticas produzidas sobre o turismo no Brasil ainda é reduzido, e, deste modo, são igualmente poucas as informações mais precisas sobre os verdadeiros impactos socioeconômicos da atividade.

No mesmo sentido, isto é, pela complexidade da atividade e pela carência de dados, a definição do que se podem considerar políticas de turismo também se torna opaca. Se tomadas em um senso estrito, as medidas que se vinculam ao turismo seriam pouco expressivas e não corresponderiam à atenção realmente despendida pelo governo sobre a atividade. Desta forma, apoiando-nos nas considerações de Cruz, que entende as políticas de turismo não apenas como uma política setorial, mas, como um "conjunto de intenções, diretrizes $e$ estratégias estabelecidas elou ações deliberadas, no âmbito do poder público, em virtude do objetivo geral de alcançar elou dar continuidade ao pleno desenvolvimento da atividade turística num dado território" (2001, p.40), procuramos compreender essas ações públicas dentro de contextos políticos mais amplos. 
O segundo aspecto a salientar é que, pela amplitude da tarefa, a análise das políticas de turismo que nos propomos não será exaustiva. De todo modo, na próxima parte do artigo buscaremos examinar a gênese dos problemas que provocam a criação ou a intensificação das políticas de turismo no país. Na terceira parte, destacaremos as principais ações implementadas e quais os pressupostos políticos que informam essas medidas. Na quarta, ilustraremos, grosso modo, os resultados esperados e encontrados das ações. Na quinta parte, iremos abordar as críticas a que estão sujeitas as políticas do segmento, e, por último, apresentaremos algumas considerações finais.

\section{O Turismo e a Construção de Políticas Públicas}

O ponto de partida desta analise é a localização do turismo no espectro de preocupações da esfera política e da ação governamental que nos servirá de parâmetro para compreender a própria forma de desenvolvimento desta atividade no período destacado. Um rápido exame das políticas de turismo no Brasil, iniciadas na década de sessenta, há de salientar a falta de definições no ordenamento público desta atividade até os anos noventa, quando se começa, de fato, a coordenar e a monitorar, mesmo com inúmeras dificuldades, o desenvolvimento do turismo nacional.

Numa perspectiva comparada, se em vários países europeus, a partir da Segunda Guerra Mundial, o turismo foi uma atividade estrategicamente estimulada por diversos governos, com o intuito de fomentar a obtenção de divisas, gerar o crescimento de determinadas regiões e de criar espaços turísticos integrados com a agricultura local (BEZERRA, 2002), no Brasil, desde a criação da Embratur (Instituto Brasileiro de Turismo) em 1966, as políticas de turismo foram precariamente explicitadas e coordenadas com outras políticas setoriais, razão porque (entre outros motivos), se resumiram, na prática, à criação de fundos e incentivos fiscais para a implantação e melhoria de infra-estrutura hoteleira (CRUZ, 2001), além de outras ações pontuais.

A transformação que começa a ocorrer a partir de 1991, representa, portanto, um grande marco da evolução do turismo no país, pois é, justamente, quando este tema surge dentro das prioridades do governo federal. Há, em decorrência disso, uma re-elaboração do papel da

\footnotetext{
${ }^{2}$ Segundo a World Tourism Organization (WTO), o turismo é o "conjunto de atividades que as pessoas realizam durante suas viagens e estadas em lugares distintos de seu entorno habitual, por um periodo de tempo
} 
Embratur e esta assume a finalidade de formular, coordenar e executar a Política Nacional de Turismo. Ademais, neste período também se iniciam os grandes programas de desenvolvimento turístico no Nordeste brasileiro, com o Prodetur (Programa de Desenvolvimento do Turismo) e as políticas de megaprojetos, tais como o Costa Dourada (Pernambuco e Alagoas) e o Linha Verde, na Bahia (CRUZ, 2001).

Um dos elementos principais para explicar as mudanças de atitudes do poder público com relação ao turismo ao longo da última década é o continuo crescimento da atividade, seja no país, seja internacionalmente. Neste sentido, contribuiu também a criação, em 1990, da World Travel \& Tourism Council (WTTC), entidade que reúne as maiores empresas mundiais do setor e que passa a exercer pressões e criar campanhas em prol do desenvolvimento do turismo, em diversos países.

Como mediadores do referencial político do turismo, tanto a WTO quanto a WTTC, na realidade, desempenham um relevante papel na construção do turismo como objeto de políticas públicas, na medida em que elaboram diversos estudos sobre a importância econômica e o crescimento da atividade no mundo - apesar do baixo grau de precisão e da superestimação dos dados apresentados ${ }^{3}$.

Ilustrando este aspecto, isto é, a expansão do turismo e a sua percepção, segundo a WTO, o número de turistas internacionais em todo o mundo aumenta de, aproximadamente, 457 milhões de pessoas, em 1990, para 698 milhões, em 2000 (2003b). Para o decênio, o mesmo organismo aponta ainda uma elevação da receita mundial gerada nas atividades turísticas de US\$ 263,3 bilhões, para US\$ 475,7 bilhões. No Brasil, as pesquisas aqui realizadas também revelam um grande incremento na entrada de turistas internacionais. Dos aproximados 250 mil visitantes no país em 1970, chega-se a 1 milhão de pessoas em 1990 e atinge-se, em 2000, o patamar de 5 milhões. Além disso, a atividade turística seria a responsável por impactar 52 segmentos da cadeia produtiva nacional, ocupando, em 1998, o equivalente a 5 milhões de pessoas e gerando uma arrecadação de tributos da ordem de US\$ 7 bilhões (CARVALHO, 2003).

consecutivo inferior a um ano, com fins de ócio, por negócios ou outros motivos" (2003a).

${ }^{3}$ É difícil apontar, com segurança, em que medida os serviços tidos como característicos do turismo são utilizados por visitantes - como os serviços de diversão de uma localidade turística - dado o baixo volume de informações estatísticas sobre estas atividades. Ilustrativa, neste sentido, é a metodologia utilizada nos trabalhos do WTTC, que se baseia na demanda gerada pelos gastos totais dos visitantes em um certo país (WTTC \& OEF, 2003). A estimativa de tais gastos, para a maioria dos países estudados, tem como referência pesquisas sobre o consumo pessoal de norte-americanos durante viagens turísticas domésticas, o que, de partida, traz a superestimação dos resultados auferidos. 
No entanto, as razões da destacada atenção recebida pelo turismo, por meio de políticas específicas, podem ser mais bem entendidas levando-se em conta os objetivos pretendidos com o seu desenvolvimento no quadro das amplas dificuldades econômicas da década de 1990, especialmente, no que se refere à vulnerabilidade externa do país, ao baixo crescimento e aos elevados níveis de desemprego (cf. CARNEIRO, 2002).

Os planos, as ações e os discursos proferidos por muitos dirigentes sobre o desenvolvimento do turismo no Brasil apresentaram em comum uma grande segurança e entusiasmo na capacidade desta atividade de gerar ganhos de divisas, elevar o nível de emprego e reduzir as disparidades regionais (BEZERRA, 2002), idéias há muito difundidas, mas pouco concretizadas de fato. Ainda que também tenham sido elencadas, a preservação ambiental, a conservação do patrimônio histórico e a promoção do bem-estar da população, são as perspectivas indicadas acima que, de maneira concreta, têm alimentado os investimentos e programas públicos voltados para o turismo no país.

Além disso, pode-se destacar que o turismo aparece para muitos atores sociais como um fenômeno cultural identificado simbolicamente com a moderna "era da globalização", ou seja, como uma espécie de porta de entrada para os governos desejosos de participar da nova ordem econômica mundial, que têm ainda, recebido a simpatia das agências multilaterais de fomento.

Faz-se importante destacar este ponto: as políticas de turismo surgem como políticas de desenvolvimento. Por este motivo, e exceto por alguns poucos casos, não há um diagnóstico preliminar da atividade turística ou de seus impactos no país, que não são apenas positivos. Há, em contrapartida, um certo tipo de deslumbramento frente aos recursos naturais nacionais e um justificado anseio de atingir o desenvolvimento socioeconômico do território particularmente nas regiões mais pobres — ambos aguçados e estimulados pelos relatórios, pela influência política, pelos interesses econômicos e pelas concepções de atores e/ou representantes da atividade.

Decorrente da mesma visão, outro aspecto essencial da gênese das políticas de turismo é o modo de encarar as dificuldades ao desenvolvimento da atividade no país. Motivados pelos aparentes benefícios e facilidades do turismo - uma enorme disponibilidade "nativa" de atrativos e uma grande capacidade de geração de renda e empregos - e, em face do marcante contraste entre a pobreza e as riquezas naturais, para muitos, o grande problema do turismo se 
constituiria no baixo aproveitamento do enorme potencial existente para a atividade ${ }^{4}$. Como aponta Carvalho (2003) era, e é, freqüente o sentimento de indignação, difundido entre as análises técnicas e em boa parte da opinião pública, frente ao fato de que o país, embora tão rico em seu cenário natural, historicamente receba um número de turistas externos menor do que países cujo território e o acervo de atrativos turísticos é visivelmente mais reduzido que o brasileiro.

No entanto, a formação dos fluxos turísticos, em especial internacionais, obedece a lógicas um pouco diferentes das que são usualmente percebidas, ou seja, vinculam-se menos a uma oferta turística latente e mais às determinações de um mercado cujas características são bastante específicas. Por ora, basta ressaltar mais uma vez que as políticas de turismo se fortalecem pelo duplo sentimento ligado à atividade: a percepção do turismo como uma grande oportunidade aberta para o desenvolvimento e a constatação de um subaproveitamento, no país, desta "inerente" oportunidade.

\section{As Políticas Públicas de Turismo na Década de 1990}

Antes de destacarmos as mais marcantes intervenções públicas no segmento, durante a década passada, é importante ressaltar o significado mais geral que acabaram por cristalizar neste processo. Embora tenham sido várias as ações implementadas, permanecem em comum dentre elas alguns traços mais profundos e determinantes.

A trajetória e o perfil do desenvolvimento do turismo no país estiveram vinculados, por um lado, a um projeto de "turismo estrangeiro", isto é, voltado para o atendimento e para a ampliação da demanda turística internacional, e, por outro lado, a uma visão liberal de desenvolvimento socioeconômico, hegemônica no cenário político brasileiro da década, a despeito do papel ativo assumido pelo Estado neste segmento. Sincronizadas com as propostas de descentralização e desregulamentação das atividades de turismo, formuladas por entidades internacionais (WTO e WTTC), as principais medidas concretizadas se direcionaram para os maiores entraves percebidos ao desenvolvimento da atividade e, em especial, ao aumento do fluxo externo de visitantes.

\footnotetext{
${ }^{4}$ Propagada por várias fontes, a grande capacidade de absorção de mão-de-obra no turismo seria expressa, por exemplo, na geração de 0,4 a 2 empregos diretos por quarto de hotel construído (Brasil, 2003).
} 
Essencialmente, o que se elaborou foram vários programas de criação de infra-estrutura básica nas localidades turísticas, projetos de aprimoramento do sistema de transportes, de estabelecimento e/ou de modernização da oferta hoteleira e de desenvolvimento do marketing do país, sobretudo no plano internacional. Permeando tais ações, também esteve presente uma preocupação com a melhoria da gestão das atividades de turismo, traduzida em sua descentralização, e alguma atenção para com a qualificação dos trabalhadores do turismo, este ainda um problema recorrente.

Feita essa observação de caráter geral, voltamos para a evolução do marco regulatório do turismo no país, iniciando com as reformas de Fernando Collor, em 1992. Temos naquele ano a criação do Decreto 448/92 que estabelece a Política Nacional de Turismo (PNT), cuja finalidade é o desenvolvimento do turismo e o seu equacionamento como fonte de renda nacional, sendo atribuídas como diretrizes desta ação a preservação do patrimônio natural e cultural e a valorização do homem como grande endereçado do desenvolvimento turístico do país (CRUZ, 2001).

Entre os objetivos específicos da PNT estavam: a democratização do acesso ao turismo nacional, pela incorporação de diferentes segmentos populacionais; a redução das disparidades socioeconômicas de ordem regional, através do crescimento do emprego e da melhor distribuição de renda; o aumento dos fluxos turísticos, das taxas de permanência e do gasto médio de estrangeiros no país, mediante maior divulgação do produto brasileiro; a difusão de novos pontos turísticos, com vistas a diversificar os fluxos de visitantes e beneficiar as regiões de menor nível de desenvolvimento; a ampliação dos serviços turísticos; o aproveitamento turístico dos recursos naturais e culturais com vistas à valorização e conservação; e, por último, a criação e implantação de equipamentos destinados às atividades de expressão cultural e outras atrações com capacidade de prolongamento da permanência dos turistas (LOBATO, 2001).

Como parte da mesma estratégia, ainda em 1992 é criado o Plano Nacional de Turismo Plantur, instrumento de implementação da política nacional composto por sete programas. Entretanto, apesar de conter algumas ações detalhadas e de revelar uma estratégia mais consistente do que as produzidas nas gestões pregressas, o Plantur não chega a sair do papel, dado o contexto de instabilidade política em que foi formulado. 
Após o governo Collor, com a consolidação do processo de reestruturação da Embratur e as mudanças mais gerais advindas do programa de estabilização econômica (Plano Real), estão postas novas bases para a política e o planejamento turístico nacional. De tal modo, em 1995, formula-se um documento completo e detalhado, que constitui um salto na regulação pública da atividade, sejam quais forem os seus méritos e defeitos. Trata-se da Política Nacional de Turismo (1996-1999), produzida durante o primeiro governo Fernando Henrique Cardoso e estendida até o seu segundo mandato.

Em sua declaração oficial, a PNT para os anos de 1996 a 1999 apresenta como grande preocupação a orientação e o ordenamento das ações do setor público para o bem-estar social. Suas idéias-força são a definição de parâmetros para o planejamento e a execução das ações dos governos estaduais e municipais e uma orientação referencial para a atuação do setor privado envolvido no segmento turístico (BRASIL/MICT, 1995). As metas esperadas com o desenvolvimento coordenado do turismo agora seriam: a melhoria da qualidade de vida dos brasileiros que vivem em regiões com potencial turístico; a diversificação qualitativa dos bens, serviços e da infra-estrutura receptiva do turismo nacional; a geração de novos empregos e a manutenção dos existentes; a qualificação e re-qualificação de recursos humanos; o aproveitamento da mão-de-obra não qualificada, com sua conseqüente capacitação; a redução de desigualdades regionais; o maior aporte de divisas ao balanço de pagamentos; a integração socioeconômica e cultural da população; a proteção ao meio ambiente e ao patrimônio; e a melhor inserção do Brasil no cenário internacional, com uma imagem mais positiva.

Com intenções bastante amplas, as ações da referida PNT contam então com quatro macroestratégias para sua execução, sendo elas, em primeiro lugar, o ordenamento, o desenvolvimento e a promoção da atividade turística pela articulação entre o governo e a iniciativa privada; em segundo, a implantação de infra-estrutura básica e de infra-estrutura turística adequada às potencialidades regionais; em terceiro lugar, a qualificação profissional dos recursos humanos envolvidos no setor; e, por último, a descentralização da gestão turística por meio do fortalecimento dos órgãos delegados estaduais e municipais e da terceirização de atividades para o setor privado. Para a operacionalização da nova política foram criados vinte e três programas específicos, além da incorporação de alguns daqueles preexistentes no país. Os programas aparecem listados, com suas respectivas metas, no Quadro I, em anexo. 
De acordo com Lobato (2001), com a adoção de tais macro-estratégias e programas, finalmente o governo posiciona-se sobre os mais agudos problemas da atividade turística no país, quais sejam, a baixa qualificação profissional e as péssimas condições de infra-estrutura. Também se destaca na PNT os programas que se vinculam à captação da demanda turística externa e aqueles cuja atenção está voltada para a articulação entre o setor público e o privado, no sentido da captação de investimentos.

Nota-se, por outro lado, um forte contraste entre os programas de ecoturismo e de municipalização do turismo, imbuídos da noção de sustentabilidade, e o direcionamento geral da PNT na consolidação do país como uma grande destinação turística internacional, dentro de um modelo de consumo de massas, associado aos grandes empreendimentos, já conhecido pelos desequilíbrios que costuma acarretar.

Em relação às políticas públicas federais ligadas ao turismo, não constantes no PNT, há ainda outros aspectos que precisam ser considerados. Do ponto de vista macroeconômico e dentro do contexto de abertura comercial da década, introduziram-se importantes mudanças quanto ao tratamento jurídico das empresas no país, buscando-se, justamente, atrair investimentos externos. Por meio de uma emenda constitucional de 1994, foram eliminadas as possibilidades de diferenciações legais entre empresas nacionais e estrangeiras atuantes no país, tornando possível o acesso das últimas às agências oficiais de crédito e aos incentivos e subsídios concedidos pelo governo.

No mesmo sentido, a crescente liberalização financeira ocorrida neste período tornou mais favorável a utilização do sistema financeiro nacional para as empresas do exterior, eliminando restrições ao uso dos recursos do Banco Nacional de Desenvolvimento Econômico e Social (BNDES). Por último, com o conjunto de reformas concretizadas pela política econômica do governo Fernando Henrique Cardoso, as condições das empresas estrangeiras viram-se ainda mais melhoradas, tanto pela extinção das proibições quanto às remessas de royalties por marcas e patentes, como pela isenção do imposto de renda sobre a remessa de lucros e dividendos por filiais de empresas estrangeiras no Brasil (LIMA, 2003).

Outras iniciativas federais, mais diretamente relacionadas ao segmento, podem ser ressaltadas. Em primeiro lugar, há a flexibilização do mercado de aviação, por meio da revisão de muitos dos acordos bilaterais, pelo aumento do número de vôos internacionais e pelo incentivo aos vôos chaters. Em segundo, houve a criação de vôos sub-regionais entre o país e nações 
vizinhas, ampliando a malha aérea entre os destinos turísticos não atendidos pelas grandes companhias aéreas. Em terceiro, houve mudanças na Lei de Cabotagem, buscando incentivar a realização de cruzeiros por navios estrangeiros na costa brasileira, que antes estavam impedidos de fazê-lo. Em quarto, diminuí-se, na Lei do Visto, as exigências para a entrada de visitantes externos. E, em quinto lugar, há um enfrentamento do cartel do transporte aéreo comercial, através de medidas como: a desvinculação dos vôos charters dos pacotes turísticos; a autorização de decolagem de vôos de empresas regionais nos aeroportos nacionais; a ampliação das concessões para novos vôos; a expansão da participação de companhias estrangeiras no mercado nacional (resultando no aumento da oferta e barateamento das passagens) e a liberalização da prática de preços, permitindo a concessão de descontos (LIMA, 2003).

Por fim, a respeito da qualificação profissional no segmento, o principal projeto implementado foi o Plano Nacional de Qualificação do Trabalhador - Turismo (PLANFOR/Turismo), do Ministério do Trabalho e Emprego (MTE). Financiado com recursos do Fundo de Amparo ao Trabalhador (FAT), seus investimentos totalizaram R\$ 35,9 milhões, entre 1997 e 1999, sendo o número de trabalhadores qualificados de 263,8 mil pessoas, em mais de 472 municípios (BRASIL/MTE, 2000).

\section{As Políticas Regionais de Turismo}

Segundo Cruz (2001), nas últimas décadas, os governos dos estados nordestinos instituíram dois tipos de políticas regionais para a atividade, com a intenção de intensificar o crescimento do turismo em seus territórios. As duas, já mencionadas, seriam o Prodetur/NE e a política de megaprojetos turísticos, ambas bastante sintonizadas com o projeto hegemônico de desenvolvimento turístico do país.

A principal característica das políticas de megaprojetos é a intensa intervenção pública estadual na tentativa de criação de grandes centros turísticos. Tendo como modelo o desenvolvimento de destinações como Cancún, que consiste na urbanização turística concentrada de áreas da costa pouco urbanizadas, a política de megaprojetos nordestina

\footnotetext{
5 Trata-se, porém, de resultados muito insuficientes às necessidades de qualificação dos trabalhadores nas atividades de turismo, que não depende apenas do treinamento mas sim, de um permanente aperfeiçoamento dos mesmos nos locais de trabalho. Destaca-se, além disso, o baixo número de encaminhamentos do programa aos postos profissionais pois, em 1999, apenas $27,4 \%$ dos formandos conseguiu a sua inserção (Brasil/MTE, 2000).
} 
envolveu quatro grandes empreendimentos, o Projeto Parque das Dunas - Via Costeira, em Natal (RN), o Projeto Cabo Branco (Paraíba), o Projeto Costa Dourada (Pernambuco e Alagoas) e o Projeto Linha Verde (Bahia). Em todos eles, os respectivos governos estaduais atuaram como protagonistas e patrocinaram, através de incentivos financeiros e fiscais, o setor privado, na ampliação da infra-estrutura hoteleira local.

O caso mais ilustrativo é o do Projeto Parque das Dunas - Via Costeira, que constituí a primeira experiência do gênero. Com a intenção de inserir Natal entre os principais destinos turísticos regionais e finalmente se distanciar da posição marginal que ocupava entre os mesmos, o governo estadual buscou expandir a infra-estrutura hoteleira da capital, através da criação de um complexo turístico de grandes proporções. Mas, sob um discurso preservacionista que também aparece nos demais projetos, foi sistematicamente ignorada a competência do governo municipal de Natal na gestão do uso de seu solo. Além da construção de uma rodovia costeira e do Parque Estadual das Dunas de Natal, o projeto contou com a implantação de dez hotéis. Ao final, as várias irregularidades no parcelamento espacial da área e a destruição da mata colocaram em xeque o discurso ambientalista de criação do projeto (CRUZ, 2001). Os resultados destacados, no entanto, se remetem mais à elevação do desembarque de passageiros em Natal e a superação das deficiências de infra-estrutura hoteleira na capital potiguar.

Num sentido bastante próximo à política de megaprojetos, o Prodetur-NE foi criado pela Superintendência de Desenvolvimento do Nordeste (Sudene) e pela Embratur em uma portaria conjunta, em 1991, tendo sido induzido pela criação do Projeto Costa Dourada e pelos acertos políticos entre Collor e os governadores de Alagoas e Pernambuco. O Prodetur, que se tornou extensivo a toda área de jurisdição da Sudene, foi concebido basicamente como um programa de inversões em infra-estrutura nos locais considerados como de elevado potencial turístico no Nordeste. Com a realização dos investimentos públicos, estava implícita a idéia de que os investimentos privados, sobretudo em hotelaria, seriam impulsionados, como de fato o foram, e assim, se consolidaria o desenvolvimento turístico da região (cf. AZZONI, 1993).

As inversões do programa destinavam-se às mais diversas áreas: saneamento, administração de resíduos sólidos, rodovias, reformas ou construção de aeroportos, desenvolvimento institucional de órgãos estaduais e municipais responsáveis pela execução do programa, preservação ambiental e recuperação do patrimônio histórico e ambiental. Por sua vez, os 
recursos do programa, orçados originalmente em US\$ 800 milhões, provinham do Banco do Nordeste (US\$ 400 milhões), como repasse do Banco Interamericano de Desenvolvimento (BID), ficando metade deste valor a cargo dos Estados e municípios envolvidos (CRUZ, 2001).

$\mathrm{Na}$ Bahia, por exemplo, os projetos definidos pelo Prodetur foram previstos apenas para as áreas prioritárias, a Costa do Descobrimento e a Costa do Cacau, mas, após algumas mudanças, a estratégia turística do Estado foi ampliada. De acordo com Simões (2002), na década de noventa, quando o turismo ganha destaque na pauta de investimentos do Estado, também ocorrem rearranjos institucionais nos órgãos ligados ao turismo e o fortalecimento dos planos de implantação de infra-estrutura nas áreas turísticas, de marketing e de educação para o turismo. Por isso, os projetos aprovados em Salvador e o seu entorno metropolitano envolveram várias ações de recuperação de patrimônio histórico (Centro Histórico e Pelourinho, entre outros), além da ampliação e modernização do Aeroporto Internacional de Salvador. Em volume de gastos, os investimentos do Prodetur/BA somaram US\$ 232,5 milhões, US\$ 130 milhões de empréstimos financiados pelo BID/BNB, US\$ 55 milhões como contrapartida estadual e US\$ 47,5 milhões do Governo Federal, através da Embratur e da Infraero.

No Ceará, o arcabouço estratégico para a implantação do Prodetur foi o diagnóstico traçado pelo Prodeturis - Programa de Desenvolvimento do Turismo em Área Prioritária do Litoral do Ceará - de 1989, que abrangeu todo o litoral do Estado e que foi concebido e administrado com verbas estaduais (COSTA, 2002). O Prodetur/CE abrangia 127 projetos, entre criação de infra-estrutura, melhoria dos transportes, recuperação de patrimônio, proteção ambiental e modernização do aeroporto Pinto Martins, em Fortaleza. Costa (2002) aponta que dois dos principais objetivos do governo estadual foram contemplados na execução do Prodetur/CE: o desenvolvimento do turismo ecológico nas regiões da serra da Ibiapaba, nos sertões do Inhamuns e no Cariri, procurando interiorizar o turismo do Estado, e a captação de eventos nacionais e internacionais, projetando o Ceará entre os destinos visados do turismo de negócios.

Além disso, em outras capitais do Nordeste, também foram inúmeros os investimentos efetuados. Como resultado, foram construídos e reformados 8 aeroportos (Porto Seguro, Lençóis, Salvador, São Luís, Aracaju, Natal, Fortaleza e Recife), ampliados e reparados 29 trechos rodoviários (totalizando $389 \mathrm{~km}$ ), realizados 17 projetos de saneamento básico, 
investidos recursos na preservação de 5.335 hectares de meio ambiente, e recuperadas várias peças do patrimônio histórico brasileiro, especialmente, em São Luís, Recife e Salvador (LIMA, 2003).

Ainda no âmbito das políticas regionais, um terceiro programa que merece especial destaque é o Programa Nacional de Municipalização do Turismo - PNMT. Como já indicado, além de buscar a descentralização no planejamento e na gestão das políticas de turismo, o programa objetivava o envolvimento e a percepção dos agentes locais quanto ao importante papel do turismo como instrumento de crescimento e de geração de empregos nas localidades com potencial turístico, capacitando a comunidade envolvida no processo de municipalização para explorá-lo de modo planejado. Também constituíram metas do PNMT o fortalecimento das relações entre os órgãos públicos e a iniciativa privada local, e a expansão de infra-estrutura nos municípios.

Subsidiando o PNMT, em 1996, a Embratur elaborou uma pesquisa para definir os critérios de seleção dos municípios prioritários para o desenvolvimento do turismo, o RINTUR (Roteiro de Informação Turística), a partir do qual seria possível focalizar a concessão de financiamentos públicos e estimular o planejamento turístico municipal. O preenchimento dos formulários da pesquisa cabia aos municípios, que, posteriormente, seriam divididos entre "Municípios Turísticos" e "Municípios com Potencial Turístico", os primeiros assim considerados quando o turismo já se encontrava consolidado na localidade, e os segundos, onde isto não ocorria. No ano 2000, os números do PNMT indicavam 1.416 municípios engajados, a realização de 236 oficinas, o treinamento de 5.900 agentes e o envolvimento de 295 mil pessoas no projeto (FIPE/EMBRATUR, 2002).

\section{O Financiamento Público do Turismo}

Crucial no desenvolvimento da atividade, as primeiras formas de crédito público projetadas para as atividades turísticas emergiram nos marcos do sistema de incentivos setoriais do país, ainda nos anos sessenta. Entre 1969 e 2000, de acordo com Embratur (2001), foram solicitados e aprovados 1433 projetos de investimentos em turismo, sobretudo no ramo hoteleiro, e liberados incentivos fiscais federais no valor total próximo ao de $\mathrm{R} \$ 700$ milhões, a preços constantes de 2000 (BEZERRA, 2002). 
Do total de projetos incentivados pelo governo federal nas últimas três décadas, cerca de $80 \%$ concentraram-se entre 1969 e 1982, mas este número correspondeu apenas a 31\% dos recursos renunciados no período. Como indica Bezerra (2002), há uma alteração quantitativa e qualitativa na concessão de incentivos fiscais federais pois, por um lado, eles deixam de ser um dispositivo comumente adotado (passando-se a priorizar um número reduzido de projetos de grande porte) e, por outro, representam percentuais cada vez maiores do valor dos investimentos, principalmente, após 1996.

Outra principal fonte de recursos para o financiamento do turismo, o Fungetur (Fundo Geral de Turismo), teve um comportamento bastante semelhante. De 1976 a 2000, foram aprovados 1145 projetos de financiamento, somando um pouco mais que R\$ 310 milhões. Em média, os valores financiados correspondiam a $46 \%$ do total dos investimentos por projeto. Tal qual o sistema de incentivos, Bezerra (2002) destaca que até meados da década de 1980 há uma concentração de $80 \%$ do número de projetos aprovados pelo fundo, atingindo-se o percentual de $50 \%$ do total de recursos que está disponível para todo o período abordado. E, do mesmo modo, a partir de então, um menor número de projetos contou com um maior volume de recursos. A despeito disso, o avanço líquido do crédito fornecido pelo fundo foi enxugado ao longo de 1990.

Com empréstimos também destinados aos investimentos de maior porte, uma vez que as operações diretas com o banco exigiam um limite mínimo de investimento de R\$ 1 milhão para as regiões Nordeste, Norte e Centro-Oeste, e de 3 milhões para as regiões Sudeste e Sul, o BNDES se torna o grande financiador de recursos públicos para as atividades de turismo, substituindo a declinante oferta de crédito fornecida pelo Fungetur. Efetivamente, através deste perfil de desembolsos, atendeu-se de modo majoritário ao ramo hoteleiro, e, em menor medida, ao subsetor de parques. Os recursos do banco para área apresentaram um aumento crescente nos primeiros anos da década e, mesmo com o declínio observado a partir de 1997, conservaram-se num patamar bastante elevado em relação ao início dos anos noventa. Curiosamente, enfatiza Bezerra (2002), este fortalecimento do BNDES como grande agente financeiro do turismo não resulta de nenhuma articulação entre a instituição e a Embratur, nos informando sobre a pouca eficácia do padrão de financiamento desenhado no período. 
Tabela 1: Financiamento do BNDES para o segmento turístico, 1990/2000*.

\begin{tabular}{|c|c|c|}
\hline Ano & Desembolsos do BNDES & Taxa de Crescimento \\
\hline 1990 & 40.436 .693 & - \\
1991 & 27.956 .477 & $(30,86)$ \\
1992 & 70.067 .252 & 150,63 \\
1993 & 76.793 .427 & 9,60 \\
1994 & 130.184 .673 & 69,53 \\
1995 & 191.755 .181 & 47,29 \\
1996 & 243.247 .315 & 26,85 \\
1997 & 293.040 .735 & 20,47 \\
1998 & 153.936 .366 & $(47,47)$ \\
1999 & 120.682 .968 & $(21,60)$ \\
2000 & 109.254 .540 & $(9,47)$ \\
\hline Total & 1.457 .355 .627 & - \\
\hline
\end{tabular}

Fonte: BNDES (2001) apud Bezerra (2002).

*Em R\$ de dezembro de 2000.

\section{Evolução do Turismo na Década de 1990}

Segundo as fontes disponíveis, o turismo doméstico no Brasil, que envolveu estimadamente um fluxo de 38 milhões de visitantes em 1998, apresentou um crescimento de $8 \%$ entre este ano e 2001, alcançando o patamar de 41,3 milhões de indivíduos nesta data (FIPE/EMBRATUR, 2002). Em relação ao fluxo turístico total, as viagens domésticas representaram uma parcela preponderante da atividade, sendo responsáveis por $78 \%$ da receita direta total gerada pelo turismo (ao todo se estima $\mathrm{R} \$ 13,2$ bilhões) e por $87 \%$ do total de turistas no país, em 1998.

Nesta época, um breve perfil do turismo doméstico nos indicava que a principal motivação das viagens era o lazer e que os meios de hospedagem utilizados eram, em maioria, as residências de parentes ou amigos (FIPE/EMBRATUR, 2002). O ônibus de linha também se sobressaía como o meio de transporte mais utilizado nas viagens, respondendo por $49,6 \%$ dos transportes, em 1998, ainda que tenha sido significativo o incremento das viagens aéreas - o número de passageiros de vôos regulares passa de 12 milhões, em 1992, para 26,5 milhões em 2000 (EMBRATUR, 2003a).

Sobre a demanda turística internacional, a despeito do crescimento mundial da atividade e da elevação do número de turistas estrangeiros no Brasil, é preciso ressaltar que ela se centraliza nas regiões do globo mais desenvolvidas economicamente. A WTO (2003b) mostra que os países ricos (EUA, França, Alemanha, Reino Unido, Japão e a China), são os maiores emissores e receptores mundiais de turistas. Reforçando este aspecto, Bezerra (2002) destaca 
que a capacidade mundial de hospedagem era de 25.640.000 leitos, em 1996. Deste total, 43,9\% encontrava-se na Europa e 35,1\% nas Américas, onde a participação dos EUA correspondia a 64\%, em 1997 (WTO apud BEZERRA 2002). Para a autora, a proximidade de um país em relação aos grandes blocos emissores de turistas é uma condição primordial de inserção nas grandes rotas do turismo internacional, como no caso do México, que recebe a visita em massa de norte-americanos. Cabe frisar, entretanto, que o turismo internacional, emissivo e receptivo, se sustenta, em muito, na taxa de câmbio praticada pelo país.

Assim, apesar do incremento do número de turistas e da receita cambial gerada ao longo de 1990, o saldo da conta turismo foi negativo em quase toda a década, devido à sobrevalorização cambial da moeda brasileira. Entre 1994 e 1998, a estabilização do Plano Real, atrelada à alta do câmbio, tornou os gastos em moeda forte e os custos das passagens aéreas internacionais relativamente baratos, incentivando o turismo emissivo internacional, situação que só é revertida após a desvalorização do câmbio em 1999.

Tabela 2: Balanço de Serviços - Conta Turismo do Brasil -1990/2000, em US\$ Mil.

\begin{tabular}{|c|c|c|c|}
\hline A nos & Receita & Despesa & Sald o \\
\hline $1990(1)$ & 1.444 .171 & 1.559 .079 & $(114.908)$ \\
$1991(1)$ & 1.558 .800 & 1.223 .569 & 335.231 \\
$1992(2)$ & 1.307 .065 & - & - \\
$1993(1)$ & 1.091 .419 & 1.892 .027 & $(800.608)$ \\
$1994(1)$ & 1.924 .800 & 2.930 .900 & $(1.006 .100)$ \\
$1995(3)$ & 2.097 .100 & 3.411 .900 & $(1.314 .800)$ \\
$1996(3)$ & 2.469 .146 & 4.438 .000 & $(1.968 .854)$ \\
$1997(3)$ & 2.594 .884 & 5.446 .000 & $(2.053 .91671)$ \\
$1998(3)$ & 3.678 .029 & 5.732 .000 & 909.144 \\
$1999(3)$ & 3.994 .144 & 3.085 .000 & 334.606 \\
$2000(3)$ & 4.227 .606 & 3.893 .000 & \\
\hline
\end{tabular}

Fontes: (1) Banco Central; (2) Dados estimados através de pesquisas; (3) Banco Central / Embratur.

Com relação a outro aspecto importante, aponta-se que o desenvolvimento do turismo foi espacialmente bastante heterogêneo. Por exemplo, em 1998, São Paulo surge como o maior destino turístico da demanda doméstica, com uma participação no fluxo do total de viagens de 4,1\% (EMBRATUR, 2003a). No plano regional, a tabela abaixo nos indica o caráter territorialmente concentrado da evolução turística no Brasil. 
Tabela 3: Maiores Regiões Emissoras e Receptoras de Turistas - Brasil, 1998/2001.

\begin{tabular}{|c|c|c|c|c|c|}
\hline \multirow{2}{*}{ Regiões } & \multicolumn{2}{|c|}{ Origem (\%) } & \multicolumn{2}{c|}{ Destino (\%) } & Relação Emis./Recp. \\
\cline { 2 - 5 } & 1998 & 2001 & 1998 & 2001 & 2001 \\
\hline Sudeste & 40,79 & 49,25 & 38,02 & 43,53 & 1,13 \\
Nordeste & 27,55 & 24,19 & 31,84 & 29,08 & 0,83 \\
Sul & 16,00 & 17,48 & 16,20 & 18,39 & 0,95 \\
Centro Oeste & 6,21 & 5,54 & 5,79 & 6,27 & 0,88 \\
Norte & 9,45 & 3,53 & 8,15 & 2,73 & 1,29 \\
Brasil & 100,00 & 100,00 & 100,00 & 100,00 & 1 \\
\hline
\end{tabular}

Fonte: FIPE/Embratur 2002.

A expansão da hotelaria também merece destaque. Segundo a Relação Anual de Informações Sociais (RAIS) os alojamentos do país passam de 14.027 unidades, em 1995, para 19.371, em 2001, crescendo 38\% neste período (EMBRATUR, 2003b). Relevante nesse crescimento é o papel desempenhado pelos órgãos de turismo no suporte à atividade, uma vez que os incentivos e mecanismos de financiamento fornecidos pelo setor público foram destinados quase exclusivamente a empresas hoteleiras, principalmente, de grande porte. Por outro lado, a tônica dada pelo aumento da competição e pelas políticas de crescimento e desregulamentação das atividades turísticas conduziu ao aumento da participação das redes internacionais no mercado interno e, com isso, a transformações nas operações do ramo de hospedagem. Em lugar das inversões imobiliárias, o capital das cadeias internacionais passou então a se concentrar na administração hoteleira, transferindo o ônus da construção e financiamento dos imóveis para os investidores domésticos. Este processo assim abriu ainda mais as possibilidades de negócios, reduzindo-se os riscos operacionais das redes, que passam a contar com maior autonomia para encerrar seus contratos de franquia.

Segundo Lima (2003), o número de hotéis das principais redes no país se eleva de 204, em 1999, para 363, em 2002 (aumento de 77\%). Já a oferta de unidades habitacionais (UH) destas empresas aumenta de 29.079 para 55.138 (ampliação de 90\%), no mesmo período. Particularmente, o número de hotéis das empresas internacionais de maior peso (Accor, Best Western, Sol Meliá, entre outras) passa de 116, em 1999, para quase o dobro (230) em 2002. Outra inovação devida às grandes redes e que constitui um marco na diversificação da oferta 
dos meios de hospedagem foi a introdução de resorts no país. Concentrados no Nordeste e demandando grandes investimentos, os resorts se caracterizam pela oferta de diversos serviços no interior do próprio empreendimento, pelo sistema de pagamento antecipado de despesas e pelo alto grau de isolamento entre os visitantes e as comunidades locais onde se situam os hotéis.

\section{Reflexões Críticas das Políticas de Turismo no Brasil}

Até aqui nos parece bastante evidente que se a principal meta das políticas de turismo implementadas era o incremento da atividade, o sucesso dessas foi garantido. Além disso, pela primeira vez há uma efetiva PNT, com diretrizes, planejamento e instrumentos para colocá-la em prática. Mas a avaliação das políticas de turismo envolve tanto a análise de quão bem sucedidos foram os planos de turismo em relação aos objetivos a que se propuseram (estes não são apenas o aumento das viagens), quanto à análise, igualmente importante, da relevância e pertinência destas ações.

O vértice central das políticas de turismo no país foi a melhora da inserção nacional no mercado turístico mundial e a dinamização da atividade no plano doméstico, por meio da desregulamentação do segmento, da descentralização e da criação de infra-estrutura turística que garantisse suporte à expansão da atividade. Para isso, seus principais instrumentos foram o Prodetur e o PNMT, além do incremento das ações de marketing internacional e das mudanças nos marcos regulatórios da atividade.

No entanto, as ações para atingir tais objetivos caminharam de modo desequilibrado. Para Luchiari e Serrano (2002) a estratégia do governo brasileiro, ao longo de toda a década, foi a de inserção do país nos mercados turísticos internacionais desenvolvendo o turismo nacional sob um "olhar do estrangeiro", em grande medida, independentemente dos interesses das populações sobre a utilização do território e mesmo desfavoravelmente ao turismo interno. A dinamização do turismo através dos programas de investimentos em infra-estrutura e da instalação de grandes hotéis deu-se então em detrimento da conservação ambiental e da participação social. Por exemplo, Cruz, num sentido próximo, aponta que:

Edifícios restaurados com recursos do Prodetur-Ne (...) mostram que a revitalização de centros históricos - via política de turismo - em capitais do Nordeste tem se reduzido, na verdade, à estandardização dessas paisagens e mesmo, à sua descaracterização (2001, p. 145). 
Além disso, esqueceu-se que a competitividade do produto turístico brasileiro no mercado internacional é marcada pelo seu distanciamento em relação aos grandes blocos emissores do turismo, ou seja, que a política de oferta turística no país deveria considerar os limites estruturais da expansão da sua demanda. E, com a enorme ênfase no mercado externo, equivocadamente, não se avaliou qual era a política cambial. A obtenção de divisas, designada como objetivo estratégico da PNT, nunca poderia ter sucesso com a política econômica de valorização da moeda, ponto chave do Plano Real.

Em relação ao PNMT, as críticas mais consistentes foram direcionadas à implementação e às falhas de concepção do projeto. A inexistência de um mapeamento confiável acerca das potencialidades turísticas do país proporcionou a inclusão de inúmeros municípios sem atrativos turísticos no programa. Disto resultou um paradoxo, no qual os municípios prioritários do programa eram a maioria dos inscritos, não havendo, portanto, qualquer prioridade. Já a falha de concepção do projeto foi a de que, ao se exortar os municípios a desenvolverem ações de planejamento de forma muito independente, colocou-se em risco as perspectivas de planejamento do turismo regional, recrudescendo-se a competição entre destinos turísticos isolados (LOBATO, 2001).

Com relação ao financiamento, Bezerra nos aponta três aspectos fundamentais que sintetizam o desempenho das políticas voltadas para esta questão: em primeiro lugar, a perda de qualidade dos diagnósticos para o segmento, relegando-se a questão do financiamento a uma posição secundária; em segundo, a fragilidade dos mecanismos criados para contrabalançar as desigualdades regionais do país, através de diferenciais de custo de crédito; e, em terceiro lugar, "(...) o fato do governo brasileiro estabelecer o turismo como uma atividade estratégica e a maior instituição de fomento, o BNDES, (...) destinar menos de 1\% de seus recursos para aplicação no setor" (2002, p.142).

Por último, é preciso destacar os impactos que a política de estímulo à expansão hoteleira internacional e de grande porte tiveram no país. Se, por um lado, os objetivos de ampliação e modernização do parque hoteleiro brasileiro, em consonância com os padrões de qualidade da demanda internacional, foram atingidos, por outro, negligenciou-se: o perfil nacional do turista doméstico; os problemas contidos no modelo hoteleiro de alto padrão implantado, que resultaram na construção de enclaves isolados das comunidades locais, muitas vezes desalojando-as de seus territórios e meios de subsistência; a pequena parcela de recursos 
próprios investidos pelas empresas internacionais, a volatilidade permitida nos contratos e suas elevadas remessas ao exterior; e os efeitos desastrosos sobre ramo hoteleiro nacional, reduzido a um papel secundário no mercado e sem condições de acompanhar o ritmo das inovações, a exemplo do ocorrido com muitos ramos econômicos do país, após a abertura comercial.

\section{Considerações finais}

É possível dizer que em seus traços gerais, a PNT compõe mais um dos pilares de sustentação de um certo modelo de desenvolvimento econômico preconizado no país, o de drive exportador, no qual sempre se encontram muito valorizados os atributos "naturais" e as vantagens comparativas como determinantes do padrão de inserção econômica internacional. Entretanto, apesar de afinada com as concepções de organismos internacionais, a PNT deveria responder aos interesses da população brasileira, que não obrigatoriamente correspondem aos de tais instituições (WTO, WTTC). Mais do que isto, tal qual a frágil idéia de que o desenvolvimento pode ser atingido com base apenas nos impulsos da exportação, desconsideraram-se os limites estruturais dos fluxos turísticos internacionais e apostaram-se recursos públicos num projeto que, senão prejudicial, é equivocado sobre muitos aspectos.

O crescimento econômico e a diminuição de desigualdades não podem ser encarados como as atribuições máximas da PNT, sob pena de condená-la ao fracasso. Se nem mesmo os investimentos, a política de financiamento e as ações de marketing foram capazes de reverter, substantivamente, a concentração territorial dos fluxos turísticos dentro do país, o que dizer da disparidade socioeconômica que estrutura a nossa organização social. As políticas de turismo, em nenhum lugar, dispõem dos instrumentos para atingir tais objetivos, que só competem à política macroeconômica e sua boa articulação como outras políticas setoriais. E, no entanto, este tem sido (demagogicamente) um dos objetivos permanentes dessas políticas.

Ora, nos parece que uma maior contribuição da PNT para promover o crescimento, gerar empregos e diminuir desigualdades sociais e regionais teria que tomar a direção oposta daquela desenhada ao longo da década e garantir o acesso da demanda turística doméstica, de baixa renda, à realização de viagens. De fato, a despeito de sua imensa massificação ao longo do século XX, a fruição ou não do turismo continua hoje como um dos fortes indícios de desigualdade social. Portanto, uma política de turismo mais condizente com os objetivos 
anunciados, que legitimam as ações adotadas, tais como o desenvolvimento econômico, a preservação do patrimônio ambiental, a valorização da cultura brasileira e a melhoria da qualidade de vida da população, têm estado muito distante da realidade encontrada em nossa história recente.

\section{Referências Bibliográficas}

AZZONI, C. R. 1993. Desenvolvimento do turismo ou desenvolvimento turístico: reflexões com base em duas regiões atrasadas em São Paulo. In: Turismo em Análise, São Paulo, v. 4, n. 2.

BEZERRA, M. M. O. 2002. Turismo e Financiamento: o caso brasileiro a luz das experiências internacionais. Campinas: Unicamp/IE, Tese de Doutoramento.

BRASIL-MTE (Ministério do Trabalho e Emprego). 2000. Planfor - Plano Nacional de Qualificação do Trabalhador: Qualificação Profissional - A Experiência na Area de Turismo. Brasília: MTE.

BRASIL-MICT (Ministério da Indústria, do Comércio e do Turismo). 1995. Política Nacional de Turismo 1996-1999. Brasília: Embratur.

CARNEIRO, R. 2002. Desenvolvimento em Crise: A Economia Brasileira no último quarto do século $X X$. São Paulo: Editora Unesp, Unicamp/IE.

CARVAlHO, C. L. 2003. A Revolução Silenciosa. Brasília: Embratur. Disponível em: $<$ www.embratur.gov.br>. Acesso em abr. 2003.

COSTA, M. M. 2002. O Setor do Turismo no Ceará: um exame do seu desempenho na década de 1990. São Paulo: Dieese-Cesit/IE/Unicamp-CNPq, Relatório de Pesquisa.

CRUZ, R. C. 2001. Política de turismo e território. São Paulo: Contexto.

EMBRATUR (Instituto Brasileiro de Turismo). 2003a. Evolução do Turismo no Brasil 1992 a 2001. Disponível em: <www.embratur.gov.br>. Acesso em ago. 2003.

. 2003b. Mão de obra empregada nas atividades turísticas RAIS (1994-2001). Disponível em: $<$ www.embratur.gov.br>. Acesso em jul. 2003.

FIPE (Fundação Instituto de Pesquisas Econômicas)/EMBRATUR. 2002. Estudo do Mercado Interno de Turismo 2001. Brasília: Embratur.

LIMA, R. A. P. F. 2003. O avanço das redes hoteleiras internacionais no Brasil. São Paulo: USP/ECA, Tese de Doutorado.

LOBATO, F. M. 2001. Descentralização das políticas de turismo: a municipalização do turismo no Maranhão. São Paulo: USP/ECA, Dissertação de Mestrado.

LUCHIARI, M. T. D. P. \& SERRANO, C. 2002. Tourism and Environment in Brazil. In: HOGAN, D. J., BERQUO, E., COSTA, H. S. M. (Eds.). Population and Environment in Brazil: Rio+10. Campinas: $\mathrm{CNPD} / \mathrm{ABEP} / \mathrm{NEPO}$. 
SIMÕES, A. M. S. 2002. Desenvolvimento Tecnológico e Mercado de Trabalho no Setor de Turismo da Bahia. São Paulo: Dieese-Cesit/IE/Unicamp-CNPq, Relatório de Pesquisa.

WTO (World Tourism Organization). 2003a. TSA in depth: Analyzing tourism as an economic activity. Disponível em: <www.world-tourism.org>. Acesso em ago. 2003.

2003.

. 2003b. Country Statistics. Disponível em: <www.world-tourism.org>. Acesso em jul.

WTTC (World Travel \& Tourism Council) \& OEF (Oxford Economic Forecasting). 2003. Methodology for producing the 2003 WTTC/OEF Travel \& Tourism Simulated Satellite Accounts. Disponível em: <www.wttc.org>. Acesso em jul. 2003.

Recebido em: 23/01/2006 (1 ${ }^{\mathrm{a}}$ versão) $10 / 04 / 2006$ ( $2^{\mathrm{a}}$ versão)

Aprovado em: 26/06/2006 
Anexo: Quadro I - Programas Federais da Política Nacional de Turismo - 1996/1999.

- Imagem do Brasil: divulgar de forma positiva a gigantesca malha de aspectos que compõe a realidade brasileira;

- "Visit Brazil": incrementar o fluxo internacional para o país atuando em mercados emissores prioritários;

- "Brazil Expert”: promoção do Brasil como destino turístico e treinamento de operadores turísticos;

- Participação em Feiras Internacionais: colocar o produto Brasil nas Feiras Internacionais de Turismo de forma competitiva;

- Captação de Eventos Internacionais: participar de forma competitiva do mercado de captação de eventos internacionais;

- Internet / Sistema de Informações Turísticas: promover a produção e disseminação de informações turísticas a nível nacional e internacional;

- Inserção Competitiva do Brasil em Fóruns Internacionais: possibilitar o processo de negociação em fóruns prioritários de interesse turístico, visando a captação de fluxos turísticos e investidores internacionais;

- Ampliação e Aperfeiçoamento do Programa de Estatísticas Básicas do Turismo: dotar o governo federal, governos estaduais e empresários ligados à atividade turística de uma base de dados estatísticos capaz de permitir o planejamento e a tomada de decisões ágeis;

- Defesa do Consumidor: realizar gestões junto a distintos órgãos públicos, federais e estaduais, visando a intensificação das normas relativas aos direitos do turista;

- Qualificação Profissional para o Turismo: fomentar a formação e a capacitação de pessoal para o desempenho de diversas funções à atividade turística;

- Conscientização e Iniciação Escolar para o Turismo: conscientizar sobre a importância socioeconômica da atividade como fator gerador de emprego e renda;

- Formação e Capacitação para o Ecoturismo: contextualizar o ecoturismo como fator de desenvolvimento sustentável e produto âncora do turismo nacional;

- Programa de Ação para o Desenvolvimento Integrado do Turismo (nacional): dotar os pólos turísticos selecionados de condições estruturais que viabilizem o estabelecimento e desenvolvimento de atividades turísticas, objetivando a geração de novos postos de trabalho;

- Programa Nacional de Ecoturismo: aproveitamento das potencialidades naturais de cada região, com vistas ao seu desenvolvimento, compatibilizado as atividades de ecoturismo 
com a conservação do meio ambiente, possibilitando a participação efetiva da comunidade e dos segmentos que atuam no setor;

- Programa de Pesca Esportiva: abrir perspectivas para a reorientação de investimentos, além de ampliar significativamente o leque de produtos à disposição dos que atuam no campo da comercialização;

- Programa Calendário Nacional dos Dias Azuis - Baixa Estação: promover o incremento do turismo doméstico, democratizando o acesso ao turismo nacional, com ofertas de pacotes turísticos mais baratos;

- Albergues da Juventude: possibilitar ao jovem o conhecimento do seu país;

- Clube da Maior Idade: melhorar o aproveitamento da oferta de equipamento turístico na baixa temporada junto ao público da $3^{\mathrm{a}}$ idade;

- Bolsa de Negócios: identificar e diversificar os pólos turísticos brasileiros e incentivar a entrada de recursos externos para investimento no setor;

- Programa Nacional de Financiamento do Turismo: promover os agentes de recursos financeiros necessários;

- Programa Nacional de Municipalização do Turismo: descentralizar a gestão da atividade turística;

- Fortalecimento dos Órgãos Delegados da Embratur: descentralização e fortalecimento do sistema oficial de turismo;

- Desenvolvimento da Malha Aérea: dotar os destinos turísticos de condições de acesso aéreo com capacidade adequada de transporte.

Fonte: Brasil/MICT, 1995. 